This report. was prepared as an account of work sponsored by an agency of the United States UC -41 Government. Neither the United States Government nor any agency thereof, nor any of their employees, makes any warranty, express or implied, or assumes any legal liability or responsibility for the accuracy, completeness, or usefulness of any information, apparatus, product, or process disclosed, or represents that its use would not infringe privately owned rights. Reference herein to any specific commercial product, process, or service by trade name, trademark, manufacturer, or otherwise does not necessarily constitute or imply its endorsement, recommendation, or favoring by the United States Government or any agency thereof. The views and opinions of authors expressed herein do not necessarily state or reflect those of the United States Government or any agency thereof.

\title{
NUCLEAR CRITICALITY SAFETY TRAINING: GUIDELINES FOR DOE CONTRACTORS
}

\author{
Author: \\ Mayme R. Crowell \\ Consultants: \\ John C. Courtney \\ Nuclear Science Center \\ Louisiana State University \\ and \\ Charles E. Newlon \\ Staff Consultant \\ $H \& R$ Technical Associates, Inc. \\ DOE/TIC- -4633 \\ DE84 001890
}

September 1983

\author{
Prepared for \\ U.S. Department of Energy \\ Assistant Secretary, Environmental Protection, \\ Safety, and Emergency Preparedness \\ Office of Nuclear Safety \\ Prepared by \\ Assessment and Field Support Programs \\ Manpower Education, Research, and Training Division \\ Oak Ridge Associated Universities
}

P.O. Box 117

Oak Ridge, Tennessee 37831

This report was prepared under contract number DE-AC05-760R00033 between the U.S. Department of

Energy and Oak Ridge Associated Universities. 


\section{DISCLAIMER}

This report was prepared as an account of work sponsored by an agency of the United States Government. Neither the United States Government nor any agency Thereof, nor any of their employees, makes any warranty, express or implied, or assumes any legal liability or responsibility for the accuracy, completeness, or usefulness of any information, apparatus, product, or process disclosed, or represents that its use would not infringe privately owned rights. Reference herein to any specific commercial product, process, or service by trade name, trademark, manufacturer, or otherwise does not necessarily constitute or imply its endorsement, recommendation, or favoring by the United States Government or any agency thereof. The views and opinions of authors expressed herein do not necessarily state or reflect those of the United States Government or any agency thereof. 


\section{DISCLAIMER}

Portions of this document may be illegible in electronic image products. Images are produced from the best available original document. 


\section{PREFACE}

The U.S. Department of Energy (DOE) Owns and operates a wide variety of nuclear facilities that support national energy, weapons, and research and development programs involving the use of nuclear material. The DOE Order 5480.1A, Chapter V, "Safety of Nuclear Facilities," establishes safety procedures and requirements for DOE nuclear facilites. This guide has been developed as an aid to implementing the Chapter $V$ requirements pertaining to nuclear criticality safety training. The guide outlines relevant conceptual knowledge and demonstrated good practices in job performance. It addresses training program operations requirements in the areas of employee evaluations, employee training records, training program evaluations, and training program records. It also suggests appropriate feedback mechanisms for criticality safety training program improvement.

The emphasis is on academic rather than hands-on training. This allows a decoupling of these guidelines from specific facilities. It would be unrealistic to dictate a universal program of training because of the wide variation of operations, levels of experience, and work environments among DOE contractors and faciliites. Hence, these guidelines do not address the actual implementation of a nuclear criticality safety training program, but rather they outline the general characteristics that should be included. 
1. INTRODUCTION $\ldots \ldots \ldots \ldots \ldots \ldots \ldots \ldots \ldots \ldots \ldots \ldots \ldots \ldots \ldots \ldots \ldots \ldots \ldots \ldots \ldots$

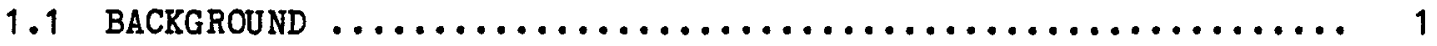

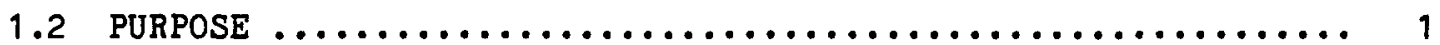

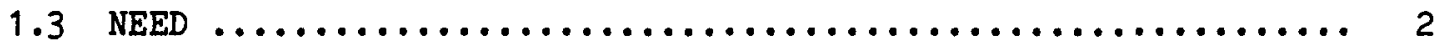

2. DEFINITIONS $\ldots \ldots \ldots \ldots \ldots \ldots \ldots \ldots \ldots \ldots \ldots \ldots \ldots \ldots \ldots \ldots \ldots \ldots \ldots$

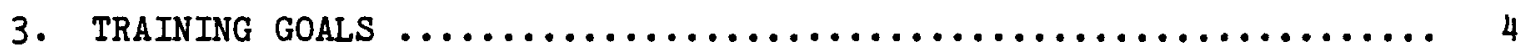

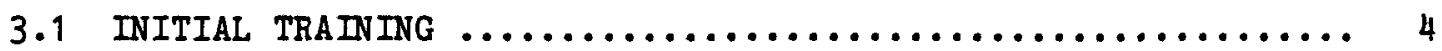

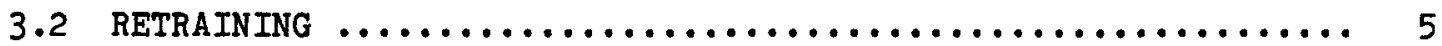

4. NUCLEAR CRITICALITY SAFETY TRAINING OBJECTIVES $\ldots \ldots \ldots \ldots \ldots \ldots \ldots$

5. NUCLEAR CRITICALITY SAFETY TRAINING TOPICAL OUTLINE FOR EQUIPMENT/PROCESS OPERATORS AND SUPPORT PERSONNEL $\ldots \ldots \ldots \ldots \ldots \ldots .10$

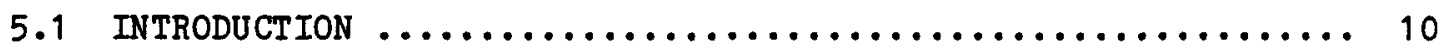

5.2 NUCLEAR THEORY AND REACTIONS $\ldots \ldots \ldots \ldots \ldots \ldots \ldots \ldots \ldots \ldots \ldots \ldots, 11$

5.2 .1 Atomic Structure $\ldots \ldots \ldots \ldots \ldots \ldots \ldots \ldots \ldots \ldots \ldots \ldots \ldots \ldots$

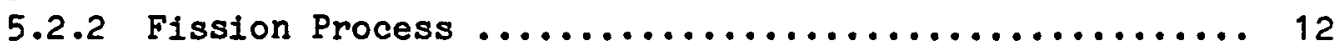

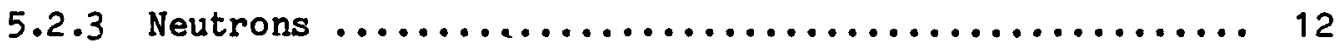

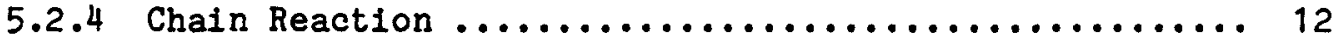

5.3 CRITICALITY CHARACTERISTICS $\ldots \ldots \ldots \ldots \ldots \ldots \ldots \ldots \ldots \ldots$

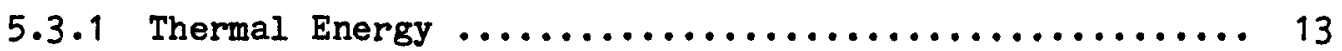

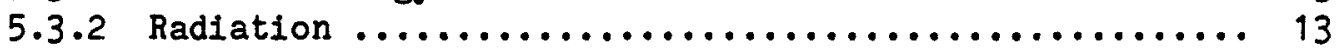

5.4 FACTORS AFFECTING CRITICALITY $\ldots \ldots \ldots \ldots \ldots \ldots \ldots \ldots \ldots \ldots \ldots$

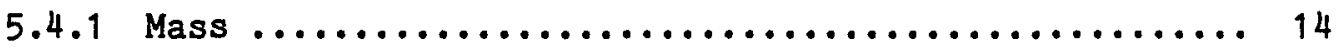

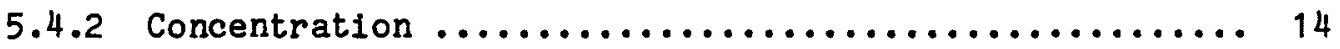

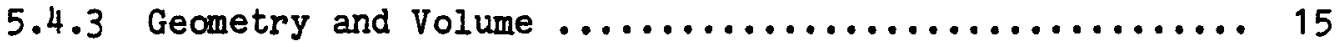

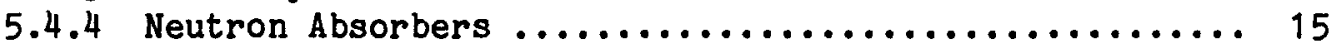

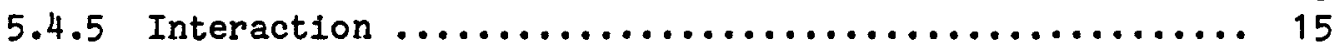

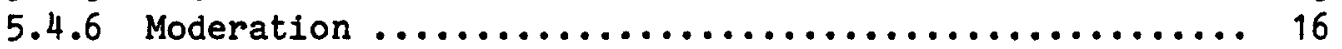

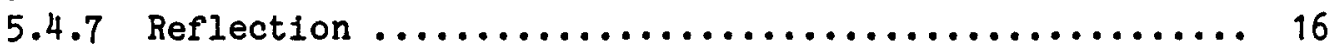

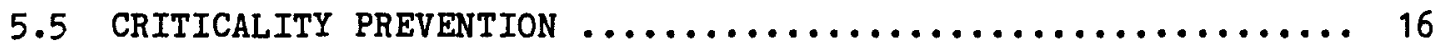

5.5 .1 Single Parameter Limits .................... 17

5.5 .2 Double Contingency Principle .................. 18

5.5.3 Administrative Control Requirements ............. 18

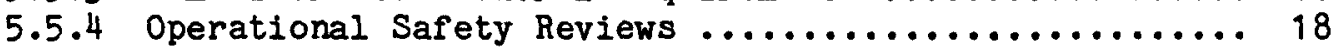

5.5.4.1 Operations Procedures Reviews ................. 18

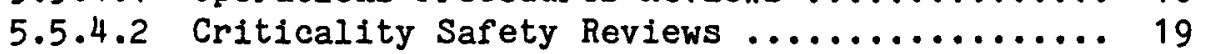

5.5 .5 General Rules ............................ 19 
5.6 EMERGENCY RESPONSE PROCEDURES $\ldots \ldots \ldots \ldots \ldots \ldots \ldots \ldots \ldots \ldots \ldots \ldots$

5.6 .1 General Responses ....................... 20

5.6 .2 Site-Specific Responses $\ldots \ldots \ldots \ldots \ldots \ldots \ldots \ldots \ldots \ldots \ldots . . \ldots 20$

5.7 CRITICALITY ACCIDENT HISTORY $\ldots \ldots \ldots \ldots \ldots \ldots \ldots \ldots \ldots \ldots \ldots \ldots$

6. NUCLEAR CRITICALITY SAFETY TRAINING PROGRAM OPERATIONS $\ldots \ldots \ldots \ldots$

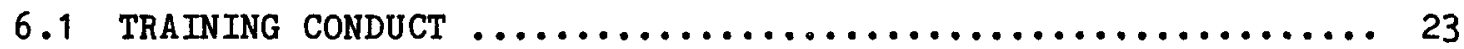

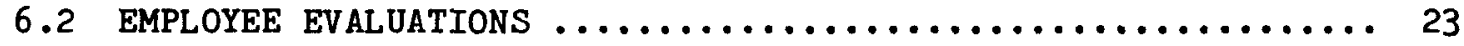

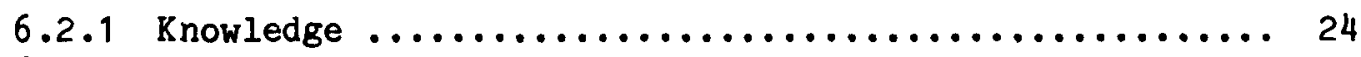

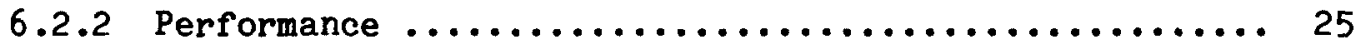

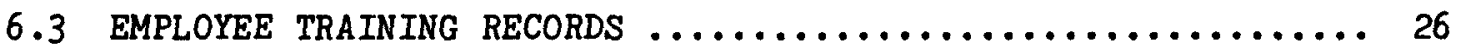

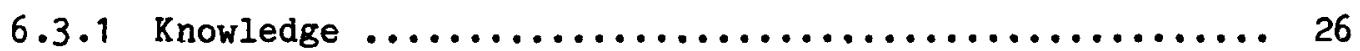

6.3 .2 Job Performance Evaluations ................... 27

6.3 .3 Medical Examinations ...................... 27

6.4 TRAINING PROGRAM EVALUATION $\ldots \ldots \ldots \ldots \ldots \ldots \ldots \ldots \ldots \ldots \ldots \ldots \ldots \ldots$

6.5 TRAINING PROGRAM RECORDS $\ldots \ldots \ldots \ldots \ldots \ldots \ldots \ldots \ldots \ldots \ldots \ldots \ldots$

7. NUCLEAR CRITICALITY SAFETY TRAINING FEEDBACK MECHANISMS ........ 29 


\section{INTRODUCTION}

\subsection{BACKGROUND}

The responsibilities of the Office of Nuclear Safety, U.S. Department of Energy, include setting safety standards and requirements and assisting DOE contractors in improving their operational safety. Safety procedures and requirements for nonreactor nuclear facilities have been established in DOE Order 5480.1A, Chapter V. The chapter includes safety requirements to assure that consideration is given to all potential criticality hazards associated with fissile material operations outside nuclear reactors. The chapter also establishes criticality safety training requirements for specific jobs related to the handing of fissile materials. In its continual effort to aid DOE contractors in complying with DOE requirements, the Office also develops and disseminates nuclear safety program guidance for the management and operation of these government-owned, contractor-operated nuclear facilities.

\subsection{PURPOSE}

The purpose of these guidelines is to provide guidance and information to DOE contractors in developing and improving both the subject matter and conduct of nuclear criticality safety training programs at their respective site locations. These guidelines identify and document the objectives and good practices, of both scope and content, based upon existing nuclear criticality safety training programs. They outline conceptual knowledge and demonstrated good criticality safety practices in job performance. These guidelines, however, do not specify on-the-job training (OJT) techniques. A suggested reference for additional guidance on establishing and implementing OJT programs is Development and Implementation of On-the-Job Iraining Programs ( INPO/TQ-501).

It is recognized that successful nuclear criticality safety training programs are possible without strict adherence to these guidelines. There is no intent to require DOE contractors to restructure their training programs to conform to either the structure, sequence, and/or format presented. Instead, these guidelines are intended for use by DOE contractors as an aid to ensure that their respective training programs reflect and implement the objectives and the most common elements of existing nuclear criticality safety training 
programs. The guidelines were prepared using current criticality safety training program information, the experience of criticality safety professionals, and nuclear industry reviewers.

\subsection{NEED}

Safety depends upon qualified personnel. Employees must understand the importance of criticality safety and must follow the safety requirements applicable to their work assignments. They must know and must follow emergency procedures. For these reasons, formal classroom training and site-specific on-the-job training are necessary to provide adequate safety assurances. Although operations procedures vary from site to site, basic concepts of criticality safety remain constant. These concepts should be incorporated into the structure of an adequate nuclear criticality safety training program.

These training program content guidelines present a generalized topical outline for criticality safety training. The amount and extent of training are not discussed, as these would be determined by specific job requirements, responsibilities, and assignments. The primary thrust of the training effort should be to provide employees with the ability to perform in a safe and productive manner.

Criticality safety training programs should be job related and based upon analyses of facility needs and job tasks. A recommended method for developing criticality safety training for specific jobs is the systems approach. The systems approach can save time and effort in the conduct of training. However, an investment of considerable resources is required to develop the training program. One such systematic method is instructional systems development (ISD), which includes designing instructional strategies based upon an analysis of job and task performance requirements. Learning objectives are established and training materials are developed and validated. The training program is then implemented with continual provisions for evaluation and feedback, especially from first-line supervisors. It is recognized that other procedures exist for developing training programs and that these other procedures may have merit. Nevertheless, the selected procedure should allow for sequential training program development and should provide adequate feedback mechanisms for continuing improvements. 


\section{DEFINITIONS}

The following definitions are used uniquely for the purpose of this document :

Nuclear Criticality Safety. Prevention of inadvertant nuclear criticality, mitigation of consequences, and protection against injury or damage due to an accidental nuclear criticality.

Guidelines. Set of components forming measurement criteria that are established to provide guidance in developing and improving both the content and conduct of training programs.

Instructional Systems Development (ISD). A systematic method of developing instructional materials for an effective training program. Four sequential phases are analysis, design, development, and implementation. The initial phase includes job and task analyses. The fifth phase, evaluation, is applied to each sequential phase.

Job and Task Analysis. The initial phase of systems approaches to training, such as instructional systems development. A job is stated in terms of the duties and tasks that comprise it.**

Lecture/Demonstration Training. Instruction designed for and presented to large or small groups at worksite locations, conference room settings, or classroom locations.

On-the-Job Training. Instruction designed for individual employees and occurring in a worksite setting with hands-on applications.

Iraining. Instruction designed and delivered to assure adequate, safe, and efficient on-the-job performance of the employee.

Work Experience. Actual job performance, simulated job performance, or work activities. Observation of others performing work is not work experience.

*For definitive information about ISD, see

U.S. Department of the Air Force. Handbook for Designers of Instructional Systems, 6 vols, AFP-50-58. Washington, D.C. (July 15, 1978).

Rosenburg, Marc J., "The ABCs of ISD." Training and Development Journal (September 1982), pp. 44-50.

* For information about use of job and task analysis procedures, see U.S. Department of Energy. Guidelines for Job and Task Analysis for DOE Nuclear Facilities, DOE/EP-0095. Washington, D.C. (June 1983). 


\section{TRAINING GOALS}

\subsection{INITIAL TRAINING}

Initial criticality safety training conveys necessary information to help prevent inadvertant nuclear criticalities and mitigate any consequences. Criticality safety training includes a broad understanding of employee responsibilities and safe work practices that are incorporated into job-specific training, whether occurring as lecture/demonstrations or at on-the-job locations.

DOE Order 5480.1A, Chapter V, requires employees at DOE-contractor sites to receive training in nuclear facility safety procedures and requirements to assure that the nuclear facilities are operated and maintained by personnel who are qualified to carry out their assigned responsibilities.

DOE contractors are required to develop, establish, and maintain criticality safety training programs which will promote an awareness of the risks involved and which will be offered at a level of proficiency consistent with assigned tasks. Specifically, this DOE order documents training and retraining requirements for all employees who operate, maintain, or supervise work in nuclear facilities. Training materials are to be prepared and documented for employees involved in the storage, transfer, and/or processing of fissile materials. Emergency procedures and plans to handle potential accidents are to be developed, disseminated, and demonstrated.

DOE Order 5480.1A, Chapter V, requires fissile materials handlers and operators to demonstrate and maintain satisfactory knowledge, when applicable to assigned job tasks, about

- normal procedures,

- emergency actions,

- radiation control practices,

- location and functions of the pertinent safety systems,

- configuration control procedures,

- procedures for making changes or alterations in the operations. 
In addition, when pertinent to the position of the employee, the order requires training, retraining, examination, and reexamination in

- standard and emergency operating procedures,

- radiological safety and control,

- safety and emergency systems,

- instrumentation and control,

- facility operating characteristics,

- principles of nuclear facility operation.

The order states that supervisors should be similarly trained and to the extent pertinent should be trained additionally on

- design, control, and operating limitations for the facility, including instrumentation characteristics, adjustment, operation, facility console control mechanisms, and control manipulations,

- procedures for making design and operating changes, including changes in operating procedures,

- radiation hazards which may arise during the performance of experiments other than those in critical assemblies,

- nuclear and radiation theory, including detalls of fission process, neutron multiplication, source effects, and neutron poison effects,

- specific operating characterstics of the facility, such as causes and effects of temperature and pressure,

- procedures and limitations involved in initial equipment loading, alterations in fissionable material configuration, and determination of various internal and external effects on reactivity,

- procedures, equipment, and facilities for handling and disposing of radioactive materials and effluents.

\subsection{RETRAINING}

DOE requirements mandate retraining programs for fissile materials handlers and personnel who operate, maintain, or supervise nuclear activities at DOE contractor sites. Verification of training and retraining must be documented by contractor management at least every two years. Employees are 
to be provided with a perlodic review of the rudiments of criticality safety and be apprised of physical facilities and procedural and equipment changes that can affect criticality safety. Emergency procedures training is required annually.

Examinations and reexaminations are an integral part of the criticality safety training process. Adequate training programs should provide for periodically evaluating the progress of each employee during the training process. Written, oral, and operating examinations are recommended. Documentation of examination results provides a means to ascertain that employees have learned presented information and have achieved the necessary qualification status to perform assigned tasks safely and proficiently. It is also important that these employee examination records be maintained in such a manner that they can be accessed and audited. 


\section{NUCLEAR CRITICALITY SAFETY TRAINING OBJECTTVES}

Employees in several job categories at the various DOE-contractor sites are required to have criticality safety training. The curricula and methods for training these employees should be based upon job-specific needs, which can be determined by job and task analyses conducted at each DOE site. The many types of facilities and operations, i.e., laboratories, uranium/plutonium processing plants, fuel storage facilities, and uranium/transuranium assembly and production facilities--all of which handle, process, and/or store fissile materials, require different job categories to perform their necessary tasks. Employees in these different job categories, however, often need similar criticality safety training to ensure that safety rules and procedures are understood and followed. Table 1 lists general criticality safety training objectives for six generic groups of job titles found at DOE-contractor sites. DOE-contractor responsibilities include determining applicable training objectives for specific jobs within each generic group and the level of knowledge required for each job within a generic group.

TABLE 1.

NUCLEAR CRITICALITY SAFETY TRAINING GENERIC GROUP TRAINING OBJECTIVES

EQUIPMENT/PROCESS OPERATORS AND SUPPORT PERSONNEL

- Chemical Operators

- Equipment Operators

- Process Operators

-Fissile Materials Handlers

- Cascade Operators

- Assembler Operators

- Machinists
-Know general criticality safety principles and specific actions required to prevent criticality.

-Know job-specific limits, controls, and procedures.

- Recognize radiation alarm systems and signals; know specific actions to be taken; demonstrate understanding of emergency response actions and plant emergency drills. - Relate causes and effects and the general characteristics of criticality.

- Know personnel to whom criticality safety concerns should be reported. - Know about major criticality accidents and lessons learned from them. - Know conditions which could lead to criticality. 
SUPERVISORY, SCIENTIFIC, AND ENGINEERING PERSONNEL

- Process Supervisors and Foremen - Project Engineers and Designers

- Laboratory Experimenters and Scientists
- Know basic information about atomic structure and radioactivity. -Know job-specific limits, controls, and procedures.

-Know issues and concerns of latest criticality safety analysis.

- Know basic princlples of criticality safety and protection standards, including those for transportation of fissile materials.

- Know causes and effects and the general characteristics of criticality.

- Recognize plant radiation alarms; know emergency response and assistance plans.

- Demonstrate knowledge of site emergency procedures and relate that information to plant equipment, processing, and handling of fissile materials.

- Know about criticality accidents and the lessons learned from them.

-Know conditions which could lead to criticality.

\section{EMERGENCY RESPONSE PERSONNEL}

- Radiation Emergency Team Members - Guards/Firefighters

- Medical Personnel
- Recognize plant radiation alarms; know emergency response and assistance plans.

- Know the nature and consequences of criticality accidents.

-Know general information about process operations and potential hazards.

-Know local emergency procedures.

- Know general radiological characteristics of criticality accidents.

- Demonstrate appropriate response actions and adequate communications techniques.
BUILDING OCCUPANTS AND GENERAL ACCESS PERSONNEL

- Casual Visitors

- New Employees

- Onsite Employees

- Vendors/Instrument Repair Persons

- Maintenance Mechanics, Welders, and Pipefitters

- Instrument Technicians

- Equipment Cleaners
- Recognize radiation alarm signals. - Know emergency response actions. - Recognize hazard identification symbols.

-Know applicable visitor control procedures. 
MANAGEMENT AND PUBLIC INFORMATION OFFICERS

- Plant Manager and Staff

- Manager of Industrial Relations and Staff

- Plant Shift Superintendent

- Manager of Nuclear Materials Accountability
- Recognize importance of criticality safety training; recognize terminology.

- Know relevant information from DOE Orders, ANS-8 Standards, and NRC regulations; know legal bases and for radiation control.

- Recognize plant radiation alarms; learn emergency response and assistance plans.

- Understand basic criticality safety principles, applicable limits, and fissile materials control symbols. - Plan for public information operations in case of an accidental criticality.

- Demonstrate appropriate response actions through the conduct of emergency response drills.

-Know about criticality accidents and lessons learned from them.
INSTRUCTORS *

- Criticality Safety Engineer

- Radiation Safety Officer

- Safety Engineer

- Training Instructor

- Consultants

-Visiting Experts
- Training objectives for instructors should be generally based on specific instructional responsibilities.
- Demonstrate thorough understanding of nuclear criticality.

- Know about criticality accidents and the lessons learned from them.

- Know relevant information from DOE Orders, ANS-8 Standards, and NRC regulations; know legal bases for radiation control. - Demonstrate understanding of criticality safety principles and applicable limits.

-Know aspects of research and development activities and general process operations and their potential hazards.

- Know issues and concerns of latest facility criticality safety analysis. - Understand facility operations using nuclear materials.

-Know local emergency procedures.

-Know site-specific and job-specific limits, controls, and procedures. - Demonstrate appropriate usage of teaching methods for group, subject matter, and site.

-Encourage feedback from trainees. 


\section{NUCLEAR CRITICALITY SAFETY TRAINING TOPICAL OUTLINE FOR EQUIPMENT/PROCESS OPERATORS AND SUPPORT PERSONNEL}

\subsection{INTRODUCTION}

This section outlines the major topics for criticality safety training for the generic group of equipment/process operators and support personnel. This generic group was selected for the outlining of a criticality safety training program because most employees requiring criticality safety training at DOE-contractor locations work in the jobs listed in this generic group.

This nuclear criticality safety training topical outline is designed to inform employees of specific hazards associated with their work environment, to indoctrinate them in the requirements applicable to their work assignments, and to teach employees how to perform effectively and efficiently required tasks without jeopardizing their own or their coworkers' safety. The topics included are based upon a review of current criticality safety training curricula at DOE-contractor sites and upon consultation with several criticality safety specialists. It is recognized that job and task analyses at specific sites or facilities may identify variations in both the scope and content of the topics identified in this guide.

Criticality safety training will occur both in the classroom and on the job. Speciflc topics and instructional settings, however, should be established according to site-specific needs.* Criticality safety professionals and trainers at DOE-contractor sites should determine the appropriate instructional topics and settings based upon site-specific needs and requirements. They should determine the amount of instructional time to devote to each topic based upon job requirements and employee training needs. The topics should be taught with the required rigor and in sufficient detail that the employees can explain their knowledge and can perform their tasks safely and effectively.

For information and guidance on assigning tasks to instructional settings, see U.S. Department of Energy. Guidelines for Job and Task Analysis for DOE Nuclear Facilities. DOE/EP-0095. Chapter 3 and Appendix C2. Washington, D.C. (June 1983). 
A nuclear criticality safety training topical outline includes the following six broad topics:

5.2 Nuclear Theory and Reactions

5.3 Criticality Characteristics

5.4 Factors Affecting Criticality

5.5 Criticality Prevention

5.6 Emergency Response Procedures in the Event of a Criticality Accident

\subsection{Criticality Accident History}

\subsection{NUCLEAR THEORY AND REACTIONS}

Concepts presented in nuclear criticality safety training require a knowledge of basic theories and terminology of nuclear physics. Only with this knowledge can an employee understand and meaningfully use terms, such as atoms, neutrons, protons, electrons, fission, isotopes, and radioactive, as a part of his or her working vocabulary. Only with this knowledge can the employee begin to conceptualize the fission process. This section provides the background materials for the understanding of criticality concepts.

\subsubsection{Atomic Structure}

This topic familiarizes the employee with basic nuclear theory. Subtopics include

- description of the atom and its parts,

- description of a fissile isotope and its behavior,

- importance of neutrons in criticality concerns,

- introduction of $\mathrm{U}$ and $\mathrm{Pu}$ atoms. 


\subsubsection{Eission Process}

This topic enables the employee to understand and appreciate the fission process. Subtopics include

- description of the fission process,

- energy released,

- radiation generated,

- radioactive materials produced.

\subsubsection{Neutrons}

This topic stresses to the employee the importance of neutrons to criticality concerns. Subtopics include

- fission caused by neutrons,

- neutron population as function of time, i.e., prompt critical, supercritical, critical, subcritical, delayed critical,

- neutron sources,

- prompt and delayed neutrons.

\subsubsection{Chain Reaction}

This topic gives the employee knowledge about a chain reaction and its relationship to criticality accidents. Subtopics include

- definition of chain reaction,

- shielded and nonshielded processes,

- critical mass,

- fissile materials, $\mathrm{U}$ and $\mathrm{Pu}$, chain reactions.

\subsection{CRITICALITY CHARACTERISTICS}

Employees need to know and recognize the conditions which can lead to a criticality incident. They need to be aware of the consequences of such conditions so that they can respond immediately and appropriately. They must realize that the buildup toward a criticality occurs with no sensory evidence. 
The criticality itself is characterized by a rapid generation of heat and the release of large quantities of radiation sometimes accompanied by a "blue flash," caused by Ionization from high intensity radiation. However, the only sure warning signal is the sound of the criticality alarm, which is designed to detect high-level radiation. This section outlines general criticality characteristics.

\subsubsection{Thermal Energy}

This topic explains that a criticality incident generates heat." Employees learn that this heat may create

- dispersal of radioactive materials in the area,

- violent ejection of fissile liquid from an open container,

- rupture of a closed, or slightly vented, container of fissile liquid because of increased pressure forcing hot, pressurized liquid and vapors in many directions,

- melting and possible ignition of fissile materials in a metallic form, if the metal is in the form of fine particles,

- vaporization of fissile materials,

- fires and explosions in surrounding materials because of the large amount of thermal energy emitted.

\subsubsection{Radiation}

This topic informs employees that the most dangerous characteristic of a criticality incident is the prompt neutron and gamma radiation. It relates the information that a person standing within a few feet of the reaction could receive a lethal radiation dose while others farther away could recelve only minimal doses. The gamma rays from the decay of the fission products can be a hazard for some time after the accident. Spread of contamination can lead to radioactive materials entering the human body. This topic includes

- three major radiation protection principles--time, distance, shielding,

- prompt radiation, neutrons and gamma rays,

* A criticality occurrence of $10^{18}$ fissions creates an immediate release of approximately $31,000 \mathrm{Btu}$ of heat. 
- radiation emitted from fission products, betas and gamma rays,

- nuclear materials as internal sources, alpha emitters,

- the relationship between distance and radiation exposure from sources,

- radiation exposure measurements,

- radiation doses and their results,

- factors affecting radiation level, such as the magnitude of reaction and the duration of criticality.

\subsection{FACTORS AFFECTING CRITICALITY}

Conditions can be controlled such that a chain reaction cannot be created or sustained. All fissile materials in nonreactor applications must be maintained at this subcritical level, which can be accomplished only through strict adherence to criticality safety controls and procedures. Factors affecting criticality are presented; namely, mass, concentration, geometry and volume, neutron absorbers, interaction, moderation, and reflection. Employees learn how and why these factors must be controlled to avoid a criticality incident. Strict compliance to posted written operating procedures is stressed.

\subsubsection{Mass}

This topic stresses to employees that the most important single factor influencing criticality is the amount of fissile material in one place at any given time. Information presented includes

- critical mass concept,

- critical mass of various fissile materials in given situations,

- methods of keeping masses as small as practicable.

\section{4 .2 Concentration}

Employees must be knowledgeable about the concentrations of fissile materials in solutions, including

- definition of concentration,

- prevention of high concentrations in any part of the system, 
- radiation emitted from fission products, betas and gamma rays,

- nuclear materials as internal sources, alpha emitters,

- the relationship between distance and radiation exposure from sources,

- radiation exposure measurements,

- radiation doses and their results,

- factors affecting radiation level, such as the magnitude of reaction and the duration of criticality.

\subsection{FACTORS AFFECTING CRITICALITY}

Conditions can be controlled such that a chain reaction cannot be created or sustained. All fissile materials in nonreactor applications must be maintained at this subcritical level, which can be accomplished only through strict adherence to oriticality safety controls and procedures. Factors affecting criticality are presented; namely, mass, concentration, geometry and volume, neutron absorbers, interaction, moderation, and reflection. Employees learn how and why these factors must be controlled to avoid a criticality incident. Strict compliance to posted written operating procedures is stressed.

\section{4 .1 Mass}

This topic stresses to employees that the most important single factor influencing criticality is the amount of fissile material in one place at any given time. Information presented includes

- critical mass concept,

- critical mass of various fissile materials in given situations,

- methods of keeping masses as small as practicable.

\subsubsection{Concentration}

Employees must be knowledgeable about the concentrations of fissile materials in solutions, including

- definition of concentration,

- prevention of high concentrations in any part of the system, 
- prevention of precipitation,

- safe concentration limits of various fissile material solutions in given situations,

- keeping solutions of fissile material as dilute as practicable.

\subsubsection{Geometry and Volume}

Since size and shape can effect criticality, this topic explains to employees that the more surface area a given volume of fissile material has, the easier it is for neutrons to escape. The probability of a criticality is discussed in terms of

- neutron escape from various shapes,

- geometric critical parameters for solids,

- geometric critical parameters for liquids.

\subsubsection{Neutron Absorbers}

This topic discusses materials that are effective neutron absorbers, i.e., those materials which aid in preventing fissions. The importance of using neutron absorbers for criticality control is stressed to employees. Information includes

- definition of neutron absorbers,

- commonly used neutron absorbers,

- usefulness in operations,

- assurance of the presence of neutron absorbers.

\subsubsection{Interaction}

Employees learn that the system of two or more masses of fissile material can become critical even though each container by itself is subcritical. Concepts include

- the interaction process,

- criticality prevention by adequate spacing, 
- criticality prevention through use of neutron-absorbing materials,

- storage and shipping contalners which prevent placement of fissile materials too close together.

\subsubsection{Moderation}

This topic explains that moderators slow down neutrons and increase their ability to cause fissions. Employees learn about

- definition of moderator,

- moderator materials,

- general use of moderation materials,

- the human body as a moderator,

- use of hydrogenous materials in such amounts that their effects counteract moderation.

\subsubsection{Reflection}

This topic includes information about materials that can scatter neutrons back into the fissile materials. Employees learn that moderators are also excellent reflectors. Points included are

- concept of reflection,

- reflection and moderation interrelationships,

- reflector materials,

- the human body as a reflector,

- reflection caused by absorber materials,

- limitation of reflection to ensure criticality safety.

\subsection{CRITICALITY PREVENTION}

Criticality prevention is inherent in criticality safety training. Prevention of criticality incidents requires careful assessment, intelifgent analyses, strategic operations planning, and strict adherence to operating procedures and administrative controls. The ranges of conditions over which a criticality can occur have been determined experimentally so that most aspects of the handling of fissile materials can be designed to prevent a criticality 
incident. Basic limits have been, or will be, established to govern operating procedures and processes. Employees who operate, maintain, or supervise activities using fissile materials at nuclear sites need adequate criticality safety information about normal plant operations and procedures. This information about plant-site operations and procedures should include

- knowledge of criticality safety principles associated with job duties,

- knowledge of how to perform routine operations using only approved procedures,

- knowledge of what parameters are expected to change during normal operations,

- knowledge of what parameters are expected not to change during normal operations,

- understanding of need for strict adherence to administrative and procedural requirements,

- understanding of what situations may result from either improper or no actions,

- being able to identify trends that can lead to abnormal operating conditions and possible safety hazards,

- mechanism for bringing criticality concerns to the attention of appropriate personnel,

- knowledge of lessons learned from unusual occurrences.

This section lists types of criticality safety limits and requirements. It reviews and elaborates upon the purpose and rationale of the development of these basic limits. The section concludes with some general rules for employees to follow to prevent criticality incidents.

\subsubsection{Single Parameter Limits}

"Safe" limits have been determined for the most common fissile materials. When appropriate, employees are presented single parameter limits, which include

- uniform aqueous solutions of fissile nuclides,

- spherical bare and reflected fissile metals and solutions,

- specific examples of single parameter concept. 


\subsubsection{Double Contingency Principle}

The double contingency principle assures that no single error or equipment malfunction can result in a criticality. Employees learn

- explanation of double contingency rule,

- examples of double contingency principle,

- normal and abnormal conditions assessments,

- applicable judgment factors.

\subsubsection{Administrative Control Requirements}

Administrative control policies are unique to each DOE-contractor site. They include procedures for handling, processing, and storing fissile materials based upon the requirements of DOE Orders, NRC regulations, and industry standards. Employees learn

- overall policy on operations and safety,

- general administrative control policies,

- requirements for specific operations processes,

- operational safety requirements.

\subsubsection{Operational Safety Reviews}

Operational safety reviews not only assure criticality safety but also enable employees to observe that criticality safety concerns are of such importance as to require continual reviews.

5.5.4.1 Operations Procedures Reviews. This topic details the process of operations procedures reviews. Employees learn that

- management reviews are conducted to ensure definite lines of responsibility and to eliminate uncertainties in procedures,

- all aspects of procedures for recelving, storing, and handling fissile materials are reviewed on a regularly scheduled basis,

- worksite procedures are retained or altered as deemed necessary for safe, efficient operations,

- written, not oral, instructions are required, 
- if any doubts exist about operations procedures, employees must stop and ask questions of their supervisors.

5.5.4.2 Criticality Safety Reviews. This topic explains situations in which criticality safety reviews are required. Employees learn that

- receiving, storing, and handling operations using fissile materials require periodic criticality safety reviews,

- any new operations involving a significant amount of fissile materials require a criticality safety evaluation,

- any revised operations procedures which involve a significant amount of fissile materials require a criticality safety review.

\subsubsection{General Rules}

It is recognized that employees will not know all the details of criticality safety limits and requirements; therefore, a set of general rules are presented and discussed. These criticality safety rules summarize what an employee should do for individual and group protection. Employees are encouraged to know and to use the following general rules:

- Follow procedures strictly.

- Never take short cuts.

- Never operate on guesswork.

- Stop work at once and notify supervision if any unusual conditions occur.

- Never make container transfers without knowing the conditions and contents of each container involved.

- Carefully check any computations and always compare results with what is anticipated.

- Never exceed the operating limits for the accumulation of fissile materials.

- Never make a configuration change to a system without an approved criticality safety procedure.

- Give detailed operations information to your supervisor or to the person replacing you on the next shift.

- Keep all records and logs current. 
- Allow only qualified persons to handle fissile materials.

- Use work stations and storage containers only in the approved and intended manner.

- Evacuate immediately if a criticality occurs.

\subsection{EMERGENCY RESPONSE PROCEDURES}

In the event of a criticality accident, employees need to know emergency response procedures. This includes

- recognition of alarms,

- knowledge of immediate emergency actions,

- understanding of consequences of taking improper or no actions,

- understanding of the bases of established emergency procedures.

\subsubsection{General Responses}

The sound of a criticality alarm, triggered automatically by neutron or gamma radiation, will usually be the first audible signal that a criticality has occurred. Employees learn that they should respond by

- leaving the building immediately, thus, putting distance between the employee and the source of radiation,

- reporting to a designated assembly area along with other building employees,

- reporting to their supervisors at the designated assembly areas,

- waiting at the assembly area for further specific instruction.

The consequences of a criticality accident are reduced substantially if employees follow these simple, step-by-step procedures.

\subsubsection{Site-Specific Responses}

Employees not only should know the general emergency responses to follow but also should learn the site-specific responses. The best method for 
teaching these site-specific responses is through criticality drills at worksite locations. Employees should learn

- what sound the criticality alarm makes,

- where to exit the building,

- where to assemble,

- methods used to report to their supervisors,

- what types of further instructions will be given.

\subsection{CRITICALITY ACCIDENT HISTORY}

A review of criticality accidents provides information about how criticalities occur and insight into how criticalities may be avoided. It demonstrates to employees that there has been a careful analysis of each accident with wide dissemination of lessons learned. This review can trace the lessons learned and can explain the development and usage of site-specific designs and practices.

Although criticality safety limits have substantial safety margins, employees must realize that criticality accidents can occur as long as the possibility of human errors and equipment malfunctions exist. The need for caution becomes evident when it is realized that no external mechanism is required to effect a criticality incident and no advance warning is given. The employee requires practical knowledge of conditions creating criticalities so as to be ever alert and careful to follow approved operations procedures. A study of criticality accident history in the nuclear industry demonstrates that such events can happen and emphasizes the need for criticality safety training.

The following criticality accidents, any one or all, can be discussed in general or in some detail to convey to employees how criticalities occur, how they may be avoided, and what lessons have been learned: 
- 1946 Los Alamos critical assembly incident

- 1951 Richland plutonium nitrate solution incident

- 1958 Oak Ridge enriched uranium recovery process incident

- 1958 Los Alamos plutonium tank transfer incident

- 1959 Idaho Falls waste collection tank incident

- 1961 Idaho Falls first-cycle product evaporator incident

- 1962 Richland plutonium accumulation from transfer tanks incident

- 1968 Oak Ridge critical experiments facility incident

- 1978 Idaho Falis uranium extraction process scrub column incident 


\section{NUCLEAR CRITICALITY SAFETY TRAINING PROGRAM OPERATIONS}

As nuclear criticality safety training program content is being designed and developed, it becomes necessary to determine how the training will be conducted and operated. This includes scheduling and conducting training, evaluating employee knowledge and performance, maintaining employee records, conducting training program evaluations, maintaining training program records, and revising training program content and operations as deemed necessary.

\subsection{TRAINING CONDUCT}

The conduct and scheduling of training are to be determined by the needs and requirements of each DOE contractor. Employees who operate, maintain, or supervise activities using fissile materials at nuclear sites require adequate, practical criticality safety information and training about normal operations and emergency procedures. Each contractor should design, conduct, and schedule job-specific, site-specific criticality safety training.

A DOE contractor criticality safety training program includes certain basic elements and specifications as listed in DOE Order 5480.1A, Chapter V. The training program is to be auditable; therefore, both the training materials and the training procedures should be documented. Criticality safety training needs and scheduling will be contingent upon operations procedures and production considerations. Each criticality safety training program should contain necessary and relevant training for the personnel involved in operating the nuclear facilities at that site. These onsite personnel include operating and maintenance employees, their supervisors, and engineering and management personnel.

\subsection{EMPLOYEE EVALUATIONS}

DOE contractor criticality safety training programs are to provide for evaluation of the progress of each employee during training. Employees are to demonstrate a satisfactory knowledge of all required subjects and procedures covered in the training program. Employee evaluations can include written, oral, and/or operational examinations as considered appropriate to the position. Examination and performance test results should be shared with each employee to enhance the learning process. An appropriate evaluation checklist 
should be provided. While the employee's immediate supervisor has first line responsibility for assessing employee job proficiency, the final verification of an employee's qualifications is to be made by senior line management or others designated by management.

It can only be ascertained if the employee has acquired the necessary criticality safety knowledge and fully understands the importance and relevance of this information to a specific job when the employee's knowledge and performance concerning criticality safety matters are evaluated. Thus, criticality safety programs include evaluations of the employee's conceptual knowledge of criticality safety and of the employee's on-the-job performance where criticality safety concerns exist. These evaluations provide verification of training to assure the necessary qualifications of an employee, both initially and continually, to perform assigned tasks in a safe and proficient manner.

\subsubsection{Knowledge}

DOE contractors need reliable, valid tests to evaluate an employee. These tests should be based upon lesson materials and learning objectives developed at each contractor site based upon specific job responsibilities and requirements. To assure their content validity, tests should be designed to include several test items on

- basic criticality theory,

- normal operating procedures,

- emergency responses,

- radiation control practices,

- configuration control,

- safety systems,

- procedures for making changes in operations.

Trainers should determine whether or not the results of tests agree with some present source of information, in particular, the employee's job performance rating. Individual test scores should confirm expected job and safety performance of employees. Trainers, or test designers, should conduct comparison studies based upon test scores and actual job performances. High test scorers should evidence top job and safety performances. Low test scores 
generally should indicate employees who are below average job and safety performers. If the comparisons show that test results are not consistent with these predictions, the test may not have criterion-oriented, predictive validity. Its usage may even be harmful, especially in terms of employee morale.

DOE contractors who are currently using a specific criticality safety training test may want to compare a newly-devised test with an established test. This procedure is practical and beneficial. However, the older established test must have proven validity, reliability, and meaningfulness to ensure adequate comparisons.

Items on any test require careful consideration and pretesting for valid, reliable results. True/false items should generally be avoided, and multiplechoice items should be checked for ambiguity, as well as for reasonable difficulty. Development of criticality safety examinations should include the necessary techniques for establishing test validity and reliability. Methods for examination management and for control of test item changes should also be established.

DOE contractors should decide if employees are required to score one hundred percent or score lower on a criticality safety test. Establishing a test pass-fail score, or cutting score, requires valid data, adequate statistical design, and value judgments. The cutting score may be determined with the scatter diagram technique, which uses data points for test scores and job performance ratings. These data indicate what degree of job performance success is to be expected from employees at each score level. A level of acceptable proficiency, a cutting score, can then be determined.

\subsubsection{Performance}

Knowledge-based tests are not the sole means of evaluating criticality safety training. Although criticality safety training enhances applicable on-the-job skills, it is quite possible for employees to know what to do but not be able to apply that knowledge to specific on-the-job situations. Therefore, it is essential to evaluate the employee's on-the-job performance of those duties that require criticality safety knowledge and applications. 
Job-specific performance evaluation methods, such as performance checklists, should be devised for the unique conditions existing at each contractor site. Evaluation reliability and validity must be established. As with knowledge-based testing, valid job-related data will be required.

\subsection{EMPLOYEE TRAINING RECORDS}

DOE contractors should maintain files of each employee's criticality safety training record. These files include the subjects covered in written, oral, and/or operating instructional settings. Records of examinations and completed checklists are to be kept and flled for each employee working in areas where the possibility of a criticality incident may occur.

This record system provides the documentation necessary to ascertain that an employee has achieved the necessary qualification status to perform assigned tasks in a safe, proficient manner. It also documents retraining schedules and results. Because a large amount of data is involved and since information retrieval needs to be adequate and efficient, computerized record systems should be considered. This employee nuclear criticality safety training record system should be designed to include information about knowledge attainment, job performance evaluations, and applicable medical examinations results.

\section{3 .1 Knowledge}

Criticality safety training records should be designed to include both test scores and test item information of individual employees in operations, maintenance, and supervisory positions where fissile materials are used. The records of completed tests and evaluations checklists are to be kept on file. Dates of training and dates of testing are required data entries. Test scores and test item information may be used to improve future tests. The completed evaluation materials for each employee will verify and document training as required by DOE Order 5480.1A., Chapter V. These records also provide necessary information for both remedial training and scheduled retraining. 


\subsubsection{Job Performance Eyaluations}

Criticality safety training records should be designed to include job performance evaluations. The job performances on individual tasks should be recorded one by one. Dates when evaluations occurred should be recorded. validation signatures, initials, or codes should appear. These job performance evaluations will provide relevant data to trainers for designing future criticality safety training materials and programs to meet employee needs and job performance requirements.

\subsubsection{Medical Examinations}

The dates of medical examinations for those employees in operations, maintenance, and supervisory positions where fissile materials are used should be recorded and maintained. The data entries and format will depend upon medical information available at each DOE-contractor site. The medical examination results should be limited to that which is necessary for criticality safety records.

\subsection{TRAINING PROGRAM EVALUATION}

DOE requires each contractor to establish and maintain an internal safety review system for its nuclear facilities. This review system should provide for the objective and independent review of nuclear facility safety training programs, including the initial and subsequent qualification and verification requirements and procedures for criticality safety. Information from employee training records and changes in plant equipment and procedures should be reflected in revisions to both training materials and training conduct. Employees completing training should be asked to evaluate the courses and instructors. Periodically, criticality safety engineers and criticality safety committees should review program content and make relevant suggestions for improvement. 


\subsection{TRAINING PROGRAM RECORDS}

Certain information should be recorded and maintained about various aspects of the criticality safety training program. These include course

- titles,

- outlines,

- Instructors,

- dates,

- durations,

- participants.

This basic information is required for adequate criticality safety training program maintenance and for DOE and contractor internal review and audit purposes. 


\section{NUCLEAR CRITICALITY SAFETY TRAINING FEEDBACK MECHANISMS}

Effective communication links should exist between criticality safety professionals and other onsite personnel. It is imperative that the criticality safety staff inform management about what resources are required to develop and maintain an effective criticality safety training program. Management accepts responsibility for site criticality safety by setting appropriate, necessary policies and by allocating time and resources for criticality safety training efforts. Criticality concerns and their implications in various operations processes should be discussed openly between operations supervisors and criticality professionals. These discussions will provide essential information for continual improvement of both operations and training. Specialists in the various safety disciplines should interactively work to reduce the chance of accidents. Information flow both to and from criticality specialists will make a good criticality safety program even better.

To operate and maintain a quality criticality safety training program requires continual feedback mechanisms. Constructive comments for the improvement of the content and/or the conduct of the criticality safety training program should be not only welcomed but also encouraged. As operations change, some aspects of criticality safety training must be altered to meet new needs. The criticality safety training program should be viewed and treated as a viable ongoing activity, not as a completed endeavor. Continual assessment, revision, and upgrading of all training components, including technical information, training materlals, and teaching methods are necessary to meet current needs and requirements. 